\title{
Revisitando el debate marxista sobre el 'derrumbe' del capitalismo. Una crítica metodológica
}

\author{
Revisiting the Marxist debate over the 'breakdown' of capitalism. \\ A methodological criticism
}

\author{
Gastón Caligaris*
}

\begin{abstract}
Resumen: En este artículo se realiza una reconstrucción crítica de la controversia marxista sobre el 'derrumbe del capitalismo' desarrollada entre las últimas décadas del siglo XIX y la década de 1930. En particular se focaliza en cómo concibieron cada una de las posiciones el vínculo entre el desarrollo económico capitalista y la acción revolucionaria de la clase obrera. Luego, se sostiene que la recuperación de las investigaciones modernas sobre el método dialéctico permite ofrecer una alternativa novedosa a las posiciones en debate.
\end{abstract}

Palabras clave: Derrumbe del capitalismo; Controversias Marxistas; Desarrollo económico; Acción política; Método dialéctico.

\begin{abstract}
This paper offers a critical reconstruction of the Marxist controversy over the 'breakdown of capitalism' developed between the last decades of the nineteenth century and the decade of 1930. In particular, it focuses on how each position in debate conceived the connection between capitalist economic development and the revolutionary action of the working class. Then, it is argued that the recovery of some modern investigations on the dialectical method allows to offer a novel alternative position to the debate.
\end{abstract}

Keywords: Breakdown of capitalism; Marxist controversies; Economic development; Political action; Dialectical method

Recibido: 23 abril 2017

Aceptado: 25 septiembre 2017

* Argentino. Doctor en Ciencias Sociales de la Universidad de Buenos Aires. Becario posdoctoral de CONICET en la Universidad Nacional de Quilmes. Contacto: gcaligaris@ gmail.com 


\section{Introducción}

El llamado debate sobre el 'derrumbe' del capitalismo ha sido una de las controversias más importantes en la historia de la teoría marxista. Por supuesto, el caso no debería resultar llamativo. En este debate se puso en discusión nada menos que los límites del capitalismo como modo de producción y las potencialidades de la acción política de la clase obrera llevar adelante su superación. Lo que sí resulta sorprendente, en cambio, es que este debate se haya simplemente diluido sin que se haya llegado a resultados concluyentes. En este trabajo me propongo realizar una reconstrucción crítica de esta controversia poniendo el foco de atención en cómo concibieron cada una de las posiciones el vínculo entre el desarrollo económico capitalista y la acción revolucionaria de la clase obrera. Según buscaré poner en evidencia a lo largo de esta reconstrucción, fue precisamente la incapacidad para precisar este vínculo lo que condujo al fracaso de esta controversia y finalmente a su desaparición en las discusiones marxistas ulteriores. En pocas palabras, mi argumento es que tanto las posiciones llamadas 'economicistas' como las 'voluntaristas' recayeron en la misma concepción respecto del vínculo entre las relaciones económicas y políticas: no alcanzaron a reconocer a este vínculo como inmanente a la reproducción de ambas relaciones sino como uno de naturaleza esencialmente exterior a las mismas. En contraposición, sugiero que la clave para superar esta limitación pasa por realizar una lectura metodológicamente fundada de la crítica marxiana de la economía política.

Este enfoque metodológico se inspira en el programa de investigación abierto por la llamada 'Nueva lectura de Marx' originada en Alemania en la década de 1970 y continuada luego en el mundo anglosajón por la llamada 'Nueva Dialéctica' a partir de la década de 1990. Estas corrientes avanzaron notablemente en la identificación del método que subyace a la crítica marxiana de la economía política llamando de este modo la atención sobre la relevancia del mismo para comprender los fundamentos de esta crítica. Sin embargo, se puede decir que nunca lograron avanzar en este programa de investigación hasta el punto de someter a examen el vínculo entre acción política y determinación económica en el momento de la superación del capitalismo. Por este motivo, en este punto recupero para mi crítica una línea de investigación reciente en la literatura especializada que, bajo una perspectiva que también se fundamenta en el método que subyace a la crítica marxiana, se ha preocupado especialmente por precisar el vínculo entre las relaciones económicas y política en la sociedad capitalista. Según procuraré demostrar en este trabajo, esta línea de investigación permite ofrecer una alternativa superadora al aparente callejón sin salida en que acabó el debate sobre el 'derrumbe' del capitalismo.

El trabajo se estructura del siguiente modo. En la primera parte se realiza una reconstrucción crítica del debate en cuestión distinguiendo cuatro etapas por la que pasó la controversia. En la segunda parte se realiza un balance del debate a la luz del método que fundamenta la crítica marxiana de la economía política y se ofrece una solución alternativa. Finalmente, en una última sección se presentan las conclusiones del trabajo. 


\section{El debate marxista sobre el derrumbe del capitalismo}

\section{El debate sobre el destino del capitalismo en Rusia (1882-1899)}

La llamada controversia sobre el "derrumbe" del capitalismo recibe su nombre de la ronda de debates que tiene lugar al interior de la socialdemocracia alemana en los años 1898-1899. ${ }^{1}$ Sin embargo, contra lo que comúnmente suele creerse, ${ }^{2}$ no es éste su origen ni su fuente más determinante y fructífera. En realidad, como lo advirtió Jacoby, ${ }^{3}$ el verdadero punto de partida de esta controversia se encuentra unos años antes en el contexto del debate ruso sobre el desarrollo del capitalismo en la Rusia zarista. En efecto, como veremos de inmediato, allí no sólo surgió la primera teoría del derrumbe del capitalismo fundada en la crítica marxiana de la economía política sino también los términos mismos que estructuraron las controversias posteriores y más conocidas.

El debate sobre el desarrollo del capitalismo en Rusia se remonta, cuando menos, al origen del populismo ruso a mediados del siglo XIX. ${ }^{4}$ No obstante, no es sino hasta que esta tradición intelectual se cruza con el naciente marxismo ruso que este debate toma cuerpo y una verdadera difusión. ${ }^{5}$ En esencia, lo que debatían los populistas rusos era si el capitalismo podía desarrollarse en Rusia de la misma manera en que lo había hecho en occidente y, más provocativamente aún, si debido a la existencia de una "comuna rural" peculiar era posible evitar el paso por el capitalismo para alcanzar una sociedad socialista. Tal como se lo presentaba Zasúlich al propio Marx, la cuestión que se les presentaba a los populistas era la siguiente, o "bien esta comuna rural" era "capaz de desarrollarse por la vía socialista" o "por el contrario, la comuna está destinada a perecer" y no queda más que "averiguar dentro de cuántos decenios tendrá el capitalismo en Rusia un desarrollo semejante al de Europa". 6

El primer intento populista dedicado a dilucidar esta cuestión sobre una base científica de inspiración marxista lo realizó Vorontsov en una serie de artículos editados

1 Lucio Colletti, "Introducción”, en Colletti, L. (comp.) El marxismo y el "derrumbe” del capitalismo, México, Siglo XXI, 1978 [1970], 13-45.

2 Véase, por ejemplo, Paul Sweezy, Teoría del desarrollo capitalista, México, Fondo de Cultura Económica, 1973 [1942]; Giacomo Marramo, "Teoría del derrumbe y el capitalismo organizado en las discusiones del "extremismo histórico", en Marramao, G., Lo político y las transformaciones. Crítica del capitalismo e ideologías de la crisis entre los años 20 y 30, México, Pasado y Presente, 1982 [1976], 73-117; Michael Krätke, "On the Beginnings of Marxian Macroeconomics", en Dellheim, J. y Frieder, O., Rosa Luxemburg: A Permanent Challenge for Political Economy, Palgrave Macmillan, 2016, 123-155.

${ }^{3}$ Russell Jacoby, "The Politics of Crisis Theory: Toward the Critique of Automatic Marxism II", Telos 23, Spring, 1975, 3-52.

${ }^{4}$ Véase, Franco Venturi, El populismo ruso, Madrid: Alianza, 1981 [1952].

5 Véase, Theodore H. Von Laue, "The Fate of Capitalism in Russia: The Narodnik Version", American Slavic and East European Review, vol. 13, n 1, 1954, pp. 11-28; Andrzej Walicki, Populismo y marxismo en Rusia, Barcelona, Editorial Estela, 1971 [1969].

${ }^{6}$ Vera Zasúlich, "Carta de Vera Zasúlich a Karl Marx del 16 de febrero de 1881”, en Marx, K y Engels, F,. Escritos sobre Rusia II. El porvenir de la comuna rusa, México, Pasado y Presente, 1980 [1881], 29. 
finalmente en su libro "El destino del capitalismo en Rusia". ${ }^{7}$ Este autor partía de una lectura de la crítica marxiana de la economía política según la cual el desarrollo del capitalismo en un país estaba sujeto a la existencia de un mercado cada vez más amplio que, por entonces, sólo podía estar garantizado por el acceso al mercado externo. Luego, al haber "entrado en el camino del progreso más tarde que otros" Rusia carecía de este acceso $\mathrm{y}$, en consecuencia, de la posibilidad de desarrollar internamente el capitalismo. ${ }^{8}$ En suma, aunque el argumento de Vorontsov buscaba probar la imposibilidad del desarrollo de capitalismo en Rusia, lo que en ante todo probaba era la inviabilidad del capitalismo mismo como modo de producción. Aunque con ligeras variantes, esta misma explicación del destino histórico del capitalismo fue adoptada rápidamente por la mayoría de los populistas. Entre ellos, su figura más destacada fue Danielson, a la sazón asiduo corresponsal de Engels y traductor de los primeros dos tomos de El Capital al ruso. "La creación de la plusvalía y su realización", escribía Danielson, "son dos cosas diferentes", es por eso "que el capitalista no podrá subsistir un día si su comercio está limitado sólo a sus necesidades y a las de sus obreros, y la nación capitalista desarrollada no podrá tampoco limitarse a su propio mercado interior". 9

Esta línea de razonamiento se topó rápidamente con severas críticas. Pero no lo hizo tanto por su falta de correspondencia con la realidad rusa sino por su inconsistencia con la explicación marxiana del capitalismo. En efecto, el punto de partida común de todas estas críticas fue defender una interpretación de la obra de Marx según la cual el capitalismo creaba sus propios mercados $\mathrm{y}$, en consecuencia, su reproducción no encontraba tales límites económicos inmanentes. Nacía de este modo la primera ronda de la controversia sobre el derrumbe del capitalismo. Las críticas más elaboradas en este sentido fueron las de Lenin, ${ }^{10}$ Tugán-Baranovski ${ }^{11}$ y Bulgákov. ${ }^{12}$ Estos autores basaron la esencia de su argumentación en una reconstrucción de los esquemas de reproducción del capital social global que Marx había diagramado en la sección tercera del segundo tomo de El Capital. En pocas palabras, el argumento común fue que, como el objetivo de la producción capitalista no es la satisfacción del consumo individual sino la valorización del valor, el plusvalor se realiza mediante el consumo productivo que amplía la escala de la producción, lo cual se expresa en la reproducción ampliada permanente de los medios de producción.

\footnotetext{
${ }^{7}$ Vasily Vorontsov, Sud'by kapitalizma v Rossii, S. Peterburg, Stasivlevicha, 1882.

${ }^{8}$ Vorontsov, op. cit., 274; citado en Richard Kindersley, The First Revisionists. A Study of Legal Marxsim in Russia, Oxford, Clarendon Press, 1962, 15.

${ }^{9}$ Nikolai F. Danielson, Histoire du Developpement économique de la Russie depuis l'Affranchissement des serfs, Paris, V. Girard and E. Briere, 1902 [1893], 252-54.

${ }^{10}$ Vladimir Ilich Lenin, "El llamado problema de los mercados", en Lenin, V. I., Obras completas. Tomo I, Madrid, Akal, 1974 [1893], 85-138; Vladimir Ilich Lenin, "El contenido económico del populismo y su crítica en el libro del señor Struve”, en Lenin, V. I., Obras completas ... op. cit. [1894], 351-523; Vladimir Ilich Lenin, "El desarrollo del capitalismo en Rusia: proceso de la formación del mercado interior para la gran industria", en Lenin, V. I., Obras Completas. Tomo III., Madrid, Akal, 1974 [1899].

${ }^{11}$ Mijaíl Tugán-Baranovski, Las crisis industriales en la Inglaterra moderna, sus causas e influencia sobre la vida social., trad. Alejandro Ariel Gonzalez, Buenos Aires, Mimeo, 2015 [1894].

12 Serguéi Nikoláievich Bulgákov, Sobre el problema de los mercados en la producción capitalista, trad. Alejandro Ariel Gonzalez, Buenos Aires: Mimeo, 2015 [1897].
} 
Así, por ejemplo, Bulgákov sostenía que "la producción capitalista es capaz de crecer ilimitadamente, a pesar de -0 incluso contra- la reducción del consumo. [...] Solo Marx ofreció el análisis del vínculo real: [...] El aumento de la producción, como ya lo hemos señalado, tiene como límite los volúmenes de capital y solo depende de éstos".13

En lecturas más célebres de este debate, las posiciones esgrimidas respecto del desarrollo del capitalismo suelen vincularse de manera más o menos directa a las perspectivas más generales adoptadas por sus principales portavoces respecto de la acción política. Así, el debate se presenta en términos de oposiciones tales como "populistas" vs. "marxistas legales" o "reformistas" vs. "revolucionarios". 14 Sin embargo, el caso es bastante más complejo. En primer lugar, muchos "populistas" eran probablemente mucho más "marxistas" que los llamados "marxistas legales"; por ejemplo, Danielson en relación a Tugán-Baranovski. En segundo lugar, y de manera determinante para el propósito de este trabajo, es importante notar que las dos posiciones que resultan del debate no se vinculan respectivamente a concepciones "reformistas" o "revolucionarias" de la transformación de la sociedad, ni mucho menos a concepciones que afirman o cuestionan la necesidad de la superación del capitalismo. Ante todo, para los populistas el diagnóstico de que el capitalismo no podía reproducirse indicaba ciertamente la posibilidad del desarrollo de la "economía campesina", pero en ningún caso la forma -reformista o revolucionaria- en que este desarrollo debía llevarse a cabo. Más expresivo de esta desconexión entre la concepción sobre el desarrollo económico y el tipo de acción política que se proponía es el caso de los críticos de los populistas. El punto salta a la vista con sólo considerar que autores tan políticamente contrapuestos como Tugán-Baranovski y Lenin compartían el mismo diagnóstico respecto de la capacidad puramente económica del capitalismo para desarrollarse y de la necesidad de la superación de este modo de producción. En efecto, ni la concepción "reformista" de uno ni la "revolucionaria" de otro estaban vinculadas con su diagnóstico común del capitalismo como un modo de producción autosuficiente desde el punto de vista de la realización económica de sus productos y al que sin embargo debía superarse. En el caso Lenin esta desconexión es tan manifiesta que, tal como lo indicaba explícitamente en su célebre ¿Qué hacer?, de la reproducción puramente económica del capitalismo no tiene cómo brotar la "conciencia socialista" que revolucione la sociedad, teniendo por eso mismo que aportarse esta conciencia "desde fuera" de dicha reproducción. ${ }^{15}$ En el mejor de los casos, tal como lo observaba en el contexto del debate que analizamos, la contradicción económica que según este autor subyace al desarrollo del capitalismo, esto es, "la contradicción entre el carácter social de la producción y el carácter individual de la apropiación", podría hacer "más fácil [...] encontrarle una salida" a este modo de producción, pero no subvertirlo por sí misma. ${ }^{16}$

\footnotetext{
${ }^{13}$ Ibid., 73.

${ }^{14}$ Por ejemplo, Rosa Luxemburg, La acumulación de capital, Buenos Aires, 1968 [1913]; Roman Rosdolsky, Génesis y estructura de El Capital de Marx, México, Siglo XXI, 1989 [1968]; Jacoby, op. cit.

15 Vladimir Ilich Lenin, “QQué hacer? Problemas candentes de nuestro movimiento”, en Lenin, V. I., Obras completas. Tomo V, Madrid, Akal, 1976 [1902], 391.

16 Vladimir Ilich Lenin, "Para una caracterización del romanticismo económico. Sismondi y nuestros sismondistas nacionales", en Lenin, V. I., Obras completas. Tomo II, Madrid, Akal, 1974 [1897], 164.
} 
En este punto, y a modo de conclusión del análisis de este primer debate sobre el "derrumbe" del capitalismo, se puede sostener que si bien la controversia se inicia poniendo el eje en las implicancias que tiene para la acción política la concepción que se adopte respecto del desarrollo económico del capitalismo, el resultado del debate es que, en cualquiera de las posiciones que se presentan, la conexión entre desarrollo económico y acción política acaba mostrándose como sumamente débil sino directamente nula. En otras palabras, en ningún caso la acción política se desprende como una necesidad inmanente del desarrollo económico.

\section{(1898-1902)}

\section{El debate sobre la "teoría del derrumbe" en la socialdemocracia alemana}

Hacia fines del siglo XIX Alemania aparecía manifiestamente formando parte de las naciones 'capitalistas' más avanzadas. Por consiguiente, la discusión entre los marxistas no pasaba por el desarrollo del capitalismo en una sociedad supuestamente 'precapitalista' sino por el modo en que el capitalismo ya dominante evolucionaba. Más precisamente, la cuestión pasaba por evaluar si la evolución del capitalismo coincidía con las tendencias generales presentadas por Marx en El Capital. Las distintas concepciones que se fueron forjando al respecto en esos años dieron lugar a lo que se llamó el "debate revisionista". ${ }^{17}$ En esencia, este debate enfrentaba a marxistas que proponían revisar y corregir las concepciones de Marx sobre la evolución del capitalismo con marxistas que procuraban defenderlas a rajatabla. En este contexto, la cuestión del "derrumbe" del capitalismo fue, si no el eje mismo de esta controversia como sugiere Colletti, ${ }^{18}$ sin duda unos de los puntos más extensa y apasionadamente discutidos. Consideremos las posiciones más relevantes.

El primero en plantear esta cuestión fue Eduard Bernstein, fundador y mayor representante de la posición 'reviosionista'. Según este autor, entre los marxistas imperaba una concepción fatalista de la superación del capitalismo cuyo eje era el derrumbe catastrófico del sistema motivado por una crisis económica insuperable. Para Bernstein, sin embargo, más que una tendencia a una crisis de esta naturaleza, la evolución histórica del capitalismo presentaba evidencias de una "adecuación" permanente del sistema y una tendencia a la eliminación de las crisis. En consecuencia, no era correcto plantear la existencia de un "derrumbe" del capitalismo. En sus palabras, "un derrumbe total y prácticamente simultáneo del actual sistema de producción no deviene más probable, sino más improbable, debido al desarrollo progresivo de la sociedad, porque ella incrementa, por un lado, la capacidad de adecuación, y por el otro $-\mathrm{o}$ bien simultáneamente-, la diferenciación de la industria”. ${ }^{19}$ De este diagnóstico Bernstein concluía que la acción política de la clase obrera, en vez de luchar por la transformación subrepticia del

${ }_{17}$ Henry Tudor y J. M. Tudor (eds.), Marxism and social democracy: the revisionist debate 1896-1898, Cambridge, Cambridge University Press, 1988.

${ }^{18}$ Lucio Colletti, "Bernstein y el marxismo de la segunda internacional", en Colletti, L. Ideología y Sociedad, Barcelona, Fontanella, 1975 [1968], 81.

19 Eduard Bernstein, "La teoría del derrumbe y la política colonial", en Bernstein, E. Las premisas del socialismo y las tareas de la socialdemocracia, México, Siglo XXI, 1982 [1898], 74. 
capitalismo, debía apuntar a luchar por reformas que eleven sus condiciones de vida y desarrollen su participación en la democracia. "La socialdemocracia", afirmaba, "no puede ansiar ni confiar en el cercano derrumbe del sistema [...] Lo que ella debe hacer, y ésta es una tarea a largo plazo, es organizar políticamente a la clase obrera y formarla para la democracia y la lucha en el estado por todas las reformas conducentes a elevar a la clase obrera". ${ }^{20}$

Las respuestas por parte de los llamados "marxistas ortodoxos" no tardaron en llegar. De acuerdo a Luxemburg, la crítica de Bernstein no cuestionaba simplemente la idea del derrumbe catastrófico del capitalismo sino asimismo el conjunto de premisas que fundamentan la necesidad del socialismo. En este sentido, la respuesta de esta autora apuntó tanto a defender la existencia de un derrumbe del capitalismo como a precisar las condiciones conducen a que, en vez de caer en una situación social irreproducible, llegue el socialismo. "En primer lugar y ante todo", sostenía Luxemburg, "la anarquía creciente de la economía capitalista [...] convierte su caída en un resultado inevitable", de ahí que sea necesario esperar un "momento en que [el capitalismo] se derrumba y se torna simplemente imposible". Pero, además, de manera paralela a esta "anarquía creciente" se desarrolla, por un lado, la "socialización del proceso de producción" y, por otro, "el poder y el conocimiento de clase crecientes del proletariado", esto es, dos condiciones sin las cuales, aun tras el derrumbe, no se podría desarrollar el socialismo. ${ }^{21} \mathrm{Su}$ punto fundamental era que Bernstein, al negar el derrumbe, acababa negando también estas dos condiciones. En el primer caso, porque la "socialización del proceso de producción" quedaba reducida a su "forma capitalista" y, en el segundo, porque "la conciencia de clase del proletariado" ya no era el "reflejo intelectual de las contradicciones cada vez más agudas del capitalismo y de su inminente caída [...] sino un mero ideal". ${ }^{22}$ De este modo, el argumento de Luxemburg parecía apuntar a vincular el derrumbe del capitalismo con la acción política revolucionaria y a la negación del mismo con la acción política reformista e impotente para trascender el modo de producción capitalista. Dejando a un lado su moderación, la respuesta de Kautsky no fue muy diferente a la de Luxemburg. "[La] forma de producción capitalista" sostenía este autor, "se hace imposible desde el momento en que el mercado no se extiende en la medida que la producción, es decir, desde que el exceso de producción se hace crónico". 23 Luego, al igual que en Luxemburg, en el argumento de Kautsky aparecía la lucha de clases para dar el paso al socialismo que el propio desarrollo económico del capitalismo era incapaz de dar. En su caso, sin embargo, el desarrollo de la lucha de clases no se fundamentaba tanto en la "anarquía de la producción" como en la "miseria" relativa creciente de la clase obrera. ${ }^{24}$ Por eso, en su presentación, la conexión entre derrumbe y lucha de clases aparecía más débil que en Luxemburg. Y a tal punto era así que, según

\footnotetext{
${ }^{20}$ Ibid., 75.

${ }^{21}$ Rosa Luxemburg, ¿Reforma o revolución?, Buenos Aires, Ediciones Luxemburg, 2010 [1899], 105.

${ }^{22}$ Ibid., 107.

23 Karl Kautsky, La doctrina socialista. Replica al libro de Eduardo Bernstein Socialismo Teórico y Socialismo Práctico, Buenos Aires, Claridad, 1966 [1899], 181-82.

${ }^{24}$ Ibid., 150 y ss.
} 
Kautsky, la lucha de clases podía provocar la caída del capitalismo aun "antes" de que se presente una situación de crisis económica terminal. "La superproducción crónica irremediable", sostiene este autor, "representa el límite extremo más allá del cual no puede subsistir ya el régimen capitalista; pero otras causas pueden hacerle sucumbir antes". Y agrega, "hemos visto que la concepción materialista, al lado de la necesidad económica, admite otros factores de la evolución social [...] que agrupamos bajo la fórmula de "lucha de clases". La lucha de clases del proletariado puede ocasionar la caída de la forma de producción capitalista antes de que llegue ésta al período de descomposición". ${ }^{25}$

El próximo paso en el debate alemán se dio apenas dos años más tarde con la publicación de la traducción al alemán de segunda edición del libro de Tugán-Baranovski sobre las crisis industriales en Inglaterra. Los argumentos principales de este libro eran los mismos de su primera edición en 1894 cuando el autor polemizaba con los populistas marxistas; en pocas palabras, que el capitalismo era un modo de producción autosuficiente y carecía de todo límite inmanente. Pero entre una edición y otra había salido a la luz el tercer tomo de El Capital y Tugán-Baranovski se había convertido en un severo crítico de Marx; en particular, de la explicación de las crisis que se ofrecía en este último tomo. Según este autor, Marx y a su turno los marxistas, consideraban que por su pura dinámica económica el capitalismo debía forzosamente llegar a un punto en que no podría reproducirse por sí mismo y que con ello se demostraba la necesidad inevitable del socialismo. "Marx creía", afirmaba Tugán-Baranovski, "que, una vez alcanzada cierta etapa de desarrollo, la sociedad capitalista no podría subsistir más. Su transformación en una sociedad socialista tendría entonces una necesidad económica. [...] Nuestro análisis de las condiciones de realización del producto social nos ha demostrado la debilidad de este punto de vista". ${ }^{26}$

La reacción contra el libro de Tugán-Baranovski fue inmediata. En este punto, los marxistas armaron un frente común asumiendo que en Marx había una teoría del derrumbe y que había que defenderla a rajatabla porque sin ella no había explicación posible para la superación del capitalismo. ${ }^{27}$ Sin embargo, aún en las repuestas más elaboradas, los marxistas no avanzaron en su argumentación mucho más allá de lo que lo habían hecho en el debate con Bernstein. En relación a la conexión entre derrumbe y acción política, también se repitieron argumentos similares, aunque esta vez portados en distintos autores. Por ejemplo, Kautsky adoptó una posición más cercana a la que había tenido Luxemburg en el debate anterior al sostener que, frente a la crisis terminal, la clase obrera "se ve obligada

\footnotetext{
25 Ibid., 185.

${ }^{26}$ Mijaíl Tugán-Baranovski, "Studies on the Theory and the History of Business Crises in England, Part I, Chapter I and VII", Research in Political Economy, vol. 18, 2000 [1901], 107-108.

${ }^{27}$ Los principales referentes fueron Conrad Schmidt, "Contribución a la teoría de las crisis comerciales y de la sobreproducción”, en Colletti, L. El marxismo ... op. cit., [1901], 177-86; Karl Kautsky, "Teoría de las crisis", Colletti, L. El marxismo ... op. cit., [1901], 189-236; Louis B. Boudin, The Theoretical System of Karl Marx in the Light of Recent Criticism, Chicago, Charles H. Kerr \& Company, 1920 [1907]. La excepción más significativa fue Hilferding que en su célebre obra "El capital financiero" recuperó, aunque con reservas, el enfoque de Tugán-Baranovski para explicar las crisis; véase, Rudolf Hilferding, El capital financiero, Madrid, Tecnos, 1963 [1910], 274 n.; 316 n.; 317 n.; 321 n.
} 
a buscar una salida para la miseria generalizada, y sólo puede encontrarla en el socialismo", aunque aún se mostraba confiado en que tal disyuntiva podía evitarse si la clase obrera conquistaba el poder "a tiempo para darle al desarrollo [económico actual] otra dirección". ${ }^{28}$ Mientras que Schimdt puso más énfasis en que la clase obrera debía conquistar el poder político antes de la crisis porque en un "ambiente social" catastrófico "las reformas económicas de tendencia socialista" podrían lograr "muy poco". 29

Consideremos cuál es el saldo que deja el debate alemán respecto del vínculo entre el desarrollo económico y la acción política. A primera vista, pareciera que con la aparición del libro de Tugán-Baranovski la posición anti-derrumbista queda definitivamente vinculada a la acción política reformista y al revisionismo. Como hemos visto, estas asociaciones son comunes en las lecturas clásicas de estos debates. Sin embargo, también aquí el caso es más complejo de lo que aparenta. En efecto, ya hemos visto que en TugánBaranovski la necesidad de una acción política reformista no surge del hecho de que el capitalismo sea un modo de producción autosuficiente. Por su parte, si se lo examina detenidamente, en el argumento de Bernstein tampoco la acción reformista brota inmanentemente de la capacidad de adecuación del capitalismo. En efecto, su argumentación no es que la capacidad de adecuación económica del capitalismo necesita de la acción reformista para llevarse a cabo. Para Bernstein la acción reformista surge sencillamente como alternativa frente a un capitalismo que por sí mismo no conduce al derrumbe porque se adapta una y otra vez. Y el caso no es distinto del lado de los llamados “derrumbistas". En Kautsky y Schmidt la desconexión entre desarrollo económico y acción política se presenta palmaria e inequívocamente en el hecho de que la clase obrera se tiene que "anticipar" a la situación de crisis terminal y, por tanto, el eventual carácter de su acción política no puede estar en absoluto conectado con tal destino final del capitalismo. En Luxemburg, si bien demuestra que la acción política reformista resulta impotente para superar el capitalismo, nada dice que la anarquía de la producción, sea más o menos aguda, vaya a motivar una acción de carácter revolucionario. En este punto, el argumento de Luxemburg no va más allá, de hecho, del argumento clásico de la socialdemocracia alemana según el cual la acción política revolucionaria brota de la creciente miseria de la clase obrero. En conclusión, pese a que se presentaron argumentos diferentes, el resultado del debate alemán no se aleja del que había dejado en este respecto el debate ruso: la conexión entre derrumbe y acción política no alcanza aquí tampoco a tener un carácter inmanente, esto es, del desarrollo económico no se desprende la necesidad ni la forma de la acción política de la clase obrera.

\section{El debate Luxemburg (1913-1924)}

La respuesta más importante que va a recibir el libro de Tugán-Baranovski va a llegar recién unos años más tarde con la aparición del libro más conocido de Luxemburg:

\footnotetext{
${ }^{28}$ Kautsky, "Teoría de las crisis..." op. cit., 233.

${ }^{29}$ Schmidt, "Contribución a la teoría..." op. cit., 185.
} 
La acumulación de capital. ${ }^{30}$ La publicación de este libro se realiza en un contexto donde comienza a emerger el debate marxista sobre el imperialismo. ${ }^{31}$ De hecho, como lo indica su subtítulo -ieliminado en las ediciones castellanas e inglesas!- con su libro esta autora se proponía realizar "una contribución a la explicación económica del imperialismo". Sin embargo, tal como lo presenta en su prólogo, lo que motivó su investigación no fue explicarse el imperialismo sino "exponer con suficiente claridad el proceso global de la producción capitalista en su aspecto concreto [y] sus límites históricos objetivos" 32 . Y, en efecto, la pregunta central que cruza toda su exposición es si la acumulación de capital tiene un límite económico inmanente más allá del cual no puede reproducirse. Por eso, el libro de Luxemburg, más que impulsar la discusión sobre el imperialismo, lo que en verdad hizo fue renovar el debate sobre el "derrumbe" del capitalismo."

Pese a la extensión y minuciosidad de su exposición, el argumento de esta autora era bastante simple. Según postulaba, el principal problema a resolver en la discusión sobre el destino del capitalismo era "de dónde ve[nía] la demanda constantemente creciente en que se fundamenta la ampliación progresiva de la producción". ${ }^{33}$ Luego, sugería que esta demanda sólo podía provenir de "un círculo de adquirentes que estén fuera de la sociedad capitalista". ${ }^{34}$ Bajo esta dinámica, concluía Luxemburg, la acumulación de capital llega a un "callejón sin salida" y se "hace imposible", y "la imposibilidad de la acumulación significa, en la producción capitalista, la imposibilidad del desarrollo ulterior de las fuerzas productivas, y, con ello, la necesidad histórica objetiva del hundimiento [Untergangs] del capitalismo". ${ }^{35}$ En este contexto, y en línea con su argumentación en el debate con Bernstein, esta autora señalaba que el socialismo sólo podía ser el resultado de la acción política revolucionaria de la clase obrera que se anticipe al derrumbe del sistema. ${ }^{36}$

Salvo contadas excepciones, la recepción del libro de Luxemburg fue absolutamente negativa. ${ }^{37}$ En Alemania, autores "revisionistas" como Schmidt, ${ }^{38}$ "centristas" como

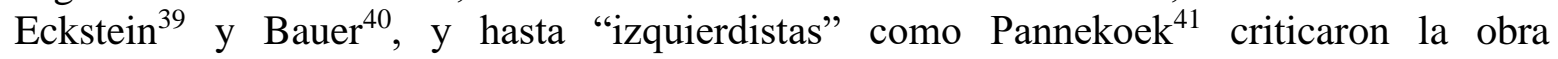

\footnotetext{
${ }^{30}$ Luxemburg, La acumulación... op. cit.

${ }^{31}$ Daniel Gaido y Manuel Quiroga, "La teoría del imperialismo de Rosa Luxemburg y sus críticos: la era de la Segunda Internacional" Critica Marxista, n 37, 2013, 113-32.

${ }^{32}$ Luxemburg, La acumulación ... op. cit., 7.

33 Ibid., 107.

${ }^{34}$ Ibid., 317.

${ }^{35}$ Ibid., 384-85.

${ }^{36}$ Ibid., 345.

${ }^{37}$ Véase Krätke, On the Beginnings ... op. cit.; Gaido y Quiroga, op. cit.

${ }^{38}$ Conrad Schmidt, "Rosa Luxemburg: Die Akkumulation des Kapitals", Archiv für Sozialwissenschaft und Socialpolitik, 39, 1915, 256-61.

${ }^{39}$ Gustav Eckstein, "Rosa Luxemburg's The Accumulation of Capital: A Critique”, en Day, R. y Gaido, D., Discovering Imperialism: Social Democracy to World War I, Leiden, Brill, 2012 [1913], 695-712.

${ }^{40}$ Otto Bauer, "La acumulación de capital", en Colletti, L. El marxismo ... op. cit. [1913], 339-64.

41 Anton Pannekoek, "Review of Rosa Luxemburg: The Accumulation of Capital: A Contribution to the Economic Explanation of Imperialism”, en Day, R. y Gaido, D. Discovering ... op . cit. [1913], 675-94.
} 
implacablemente. Y en Rusia, sentencia de Lenin mediante, ${ }^{42}$ los bolcheviques también rápidamente la desestimaron. En esencia, todas estas críticas apuntaron a defender una interpretación de la explicación de Marx de la dinámica de la acumulación de capital en donde el plusvalor no necesitaba realizarse por medio de agentes externos al propio capital. En otras palabras, apuntaron a negar la existencia de un derrumbe del capitalismo motivado por una imposibilidad puramente económica de realización del plusvalor al interior de la sociedad capitalista. En relación a la conexión entre desarrollo económico y acción política, los críticos de Luxemburg no realizaron innovaciones respecto a instancias anteriores al debate. Más llamativo aún es que, viniendo de posiciones políticas tan diversas, estos críticos acabaran presentando posiciones muy similares en relación a esta conexión. Consideremos especialmente a las dos críticas que se convirtieron en el curso del debate en las respuestas "oficiales" al enfoque luxemburgista dadas por la socialdemocracia alemana $^{43}$ y por los bolcheviques ${ }^{44}$ respectivamente, y que por lo demás son expresiones de posiciones políticas abiertamente contrapuestas.

Respecto a la cuestión de la superación del capitalismo la respuesta de la socialdemocracia alemana se limita a recuperar su línea de argumentación histórica presente desde el programa de Erfurt $^{45}$ y luego esgrimida por Kautsky en su respuesta a Bernstein. En pocas palabras, la clase obrera reaccionará frente a sus condiciones crecientemente empobrecidas tomando el poder político del Estado e imponiendo el socialismo. "El capitalismo", decía Bauer "no fracasará a causa de la imposibilidad mecánica de realizar el plusvalor. Sucumbirá, en cambio, a la rebelión hacia la cual impulsa a las masas del pueblo". ${ }^{46}$ A primera vista, puede resultar llamativo que Bauer pueda recuperar esa línea de argumentación tomando una posición contraria a la teoría del derrumbe del capitalismo, pues como se recordará esta posición anti-derrumbista era la que tenían los "revisionistas" y contendientes de Kautsky. Sin embargo, Bauer puede realizar esta operación precisamente porque, como también hemos visto, en dicha línea de argumentación la conexión entre derrumbe y acción política revolucionaria de la clase obrera es sumamente débil. ${ }^{47}$ De parte de los bolcheviques la respuesta no es muy diferente. En esencia, esta crítica pasa por presentar a la guerra imperialista como la causa de la miseria y, a su turno, de la rebelión de la clase obrera contra el capitalismo. "Hoy ya

${ }^{42}$ Vladimir Ilich Lenin, "Letter To the Editor of Bremer Bürger-Zeitung”, en Lenin, V. I, Collected Works. Vol. 43, Moscow, Progress Publishers, 1977 [1913], 332-33; Vladimir Ilich Lenin, "Carta a la redacción del periódico Sotsial-Demokrat”, en Lenin, V. I, Correspondencia. Tomo II, Buenos Aires, Editorial Estudio, 1968 [1913], 88-89; Vladimir Ilich Lenin, “Carlos Marx (Breve esbozo biográfico con una exposición del marxismo)”, en Lenin, V. I., Obras completas. Tomo XXII, Madrid, Akal, 1977 [1915], 181-82.

${ }^{43}$ Bauer, La acumulación ... op. cit.

${ }^{44}$ Nikolai Bujarin, El imperialismo y la acumulación de capital, Buenos Aires, Tiempo Contemporáneo, 1974 [1924].

${ }^{45}$ Karl Kautsky, The Class Struggle (Erfurt Program), Chicago, C. H. Kerr \& Co-Operative, 1910 [1892].

${ }^{46}$ Bauer, "La acumulación de capital" ... op. cit., 363.

47 Asimismo, dicho sea de paso, tal es la base sobre la que el Kautsky de posguerra podrá cambiar radicalmente su posición respecto al derrumbe del capitalismo sin modificar su concepción general sobre el vínculo entre las relaciones económicas y políticas; véase Karl Kautsky, The Materialist Conception of History, New Haven, Yale University Press, 1988 [1927], 424-56. 
estamos en condiciones de permitirnos emitir juicio, sobre el proceso del derrumbe capitalista, que no se base ya simplemente en construcciones abstractas y perspectivas teóricas. El derrumbe del capitalismo se ha iniciado", sostenía Bujarín. "La revolucionarización del proletariado tuvo que ver, indudablemente, con la ruina económica, ésta con la guerra, la guerra con la [...] política imperialista en general". ${ }^{48}$ En suma, al igual en el caso de los socialdemócratas alemanes, para Bujarin la acción política revolucionaria de la clase obrera, y por tanto la superación del capitalismo, surgía de las condiciones crecientemente miserables a las que se ve sometida la clase obrera en este modo de producción.

Escrita en 1915 y publicada póstumamente en 1921, la respuesta de Luxemburg a sus críticos -popularmente conocida como la Anticrítica- repite esencialmente los mismos argumentos que su obra original. ${ }^{49}$ Lo interesante de esta respuesta, tal como lo observa agudamente Jacoby, ${ }^{50}$ es que aquí Luxemburg se defiende particularmente contra la acusación de economismo y mecanicismo. En este punto, la defensa de esta autora pasa por sostener que la tendencia económica al derrumbe del capitalismo no lleva por sí misma al socialismo; que lo que se necesita ante todo es de la acción política revolucionaria de la clase obrera y, más precisamente, que esta acción se lleva a cabo antes de que acontezca efectivamente dicho derrumbe motivada por una situación económica crecientemente insostenible. "La tendencia objetiva de la evolución capitalista hacia tal desenlace" sostenía Luxemburg "es suficiente para producir mucho antes una tal agudización social y política de las fuerzas opuestas, que tenga que poner término al sistema dominante". ${ }^{51} \mathrm{Si}$ se lo examina detenidamente, el argumento de Luxemburg respecto del vínculo entre el derrumbe y la acción política revolucionaria no es muy diferente del que esgrimía en su debate contra Bernstein. Lo interesante de esta nueva presentación no sólo es que es mucho más precisa que la anterior, sino que se da en un contexto de acusación de "economicismo" y "mecanicismo" que obliga a dar cuenta del vínculo preciso que hay entre el desarrollo económico y la acción política. En este sentido, se puede decir que la argumentación de Luxemburg responde convincentemente a la acusación de sus críticos al incluir a la acción política de la clase obrera como un momento necesario de la superación del capitalismo. Sin embargo, la conexión de esta acción con el desarrollo económico continúa siendo sumamente débil y, en esencia, de la misma naturaleza que la conexión que presentan sus críticos: la situación económica crítica, que se desarrolla por sí misma, motiva la acción revolucionaria al hacer visible el estado miserable en que se encuentra la clase obrera. En otras palabras, no es que el propio proceso económico necesita de la acción política revolucionaria de la clase obrera para desarrollarse, sino que por un lado existe el desarrollo económico y por otro la acción política revolucionaria que se opone a él. ${ }^{52}$

\footnotetext{
${ }^{48}$ Bujarin, El imperialismo ... op. cit., 129-30.

${ }^{49}$ Rosa Luxemburg, "La acumulación de capital o en qué han convertido los epigonos la teoría de Marx. Una anticrítica”, en Luxemburg, R., La acumulación ... op. cit., 437-547.

${ }^{50}$ Jacoby, The Politics of Crisis ... op. cit.

${ }^{51}$ Luxemburg, "La acumulación de capital o en qué han convertido ... op . cit., 470.

52 En este sentido, no parece casual que la célebre frase "Socialismo o Barbarie" con la que se recuerda el enfoque de Luxemburg sobre el derrumbe no perteneciese a Engels, como pensaba esta autora (véase, Rosa
} 
En suma, si consideramos cómo se presenta la cuestión del vínculo entre desarrollo económico y acción política en esta instancia del debate nos encontramos otra vez con resultados similares a los que arribamos en instancias anteriores. Pero ahora el escenario está más claramente definido. No sólo en ninguna de las dos posiciones en disputa alcanzó a presentar una conexión inmanente entre desarrollo económico y acción política, sino que ambas posiciones acabaron presentando exactamente la misma conexión exterior: por un lado, está el desarrollo económico que conduce por sí mismo a una situación crítica; por el otro, está la clase obrera que reacciona frente a esta situación.

\section{El debate Grossmann (1929-1934)}

El último estertor del debate sobre el derrumbe tuvo lugar con la publicación del libro de Grossmann, La ley de la acumulación y del derrumbe del sistema capitalista ${ }^{53}$ en el contexto de la crisis económica europea de la década de $1920 .{ }^{54}$ De acuerdo a este autor, la acumulación de capital lleva consigo la tendencia hacia su propio derrumbe, pero no lo hace por un problema de realización del plusvalor, como hasta entonces habían sostenido los adherentes a la teoría del derrumbe, sino de falta de plusvalor para satisfacer las necesidades de la prosecución de la propia acumulación de capital. Llegado cierto punto, concluye Grossmann, "los capitalistas deberán alimentarse del aire [...] el sistema sufre un colapso, la crisis del sistema que sobreviene de este modo expresa el derrumbe la de la valorización". 55 Lo que explica este derrumbe, como lo precisa más adelante, es que la acumulación "se desenvuelve en base a una composición orgánica del capital progresivamente creciente", de modo que el plusvalor producido, aún con una población creciente, "siempre aumenta menos que el capital". 56

Lo interesante del enfoque de Grossmann no sólo es que saca el foco de análisis del derrumbe del problema de la realización del plusvalor, ${ }^{57}$ sino que asimismo termina por cambiar el foco del problema del vínculo entre el desarrollo económico y la acción política sacándolo de la disyuntiva "reformismo" o "revolución" para situarlo en la de

Luxemburg, "El folleto Junius: la crisis de la socialdemocracia alemana", en Obras Escogidas de Rosa Luxemburg, Izquierda Revolucionaria, 2008 [1916], 278.), sino a Kautsky, cuyo enfoque se presentaba en las antípodas del de Luxemburg. Al respecto véase Ian Angus, "The origin of Rosa Luxemburg's slogan 'socialism or barbarism"', en John Riddell's Marxist Essays and Commentary, [en línea] <https://goo.gl/qzMGqL>.

${ }^{53}$ Henryk Grossmann, La ley de la acumulación y del derrumbe del sistema capitalista, México, Siglo XXI, 1979, [1929]. Dejamos a un lado aquí la influyente obra de Frtiz Sternberg, El imperialismo, México, Siglo XXI, 1979 [1926] en la medida en que, por una parte, no avanza sustantivamente en los argumentos que había presentado Luxemburg en su Acumulación de capital y, por otra, en que es rápidamente desplazada en el debate por la aparición de la referida obra de Grossmann.

${ }^{54}$ Sobre este contexto histórico véase Ester Fano, "Los países capitalistas, desde la guerra mundial hasta la crisis de 1929" en AA.VV., La crisis del capitalismo en los años '20. Análisis económico y debate estratégico en la tercera internacional, México, Pasado y Presente, 1981 [1976], 91-131.

${ }^{55}$ Ibid., 83.

${ }^{56}$ Ibid., 120.

57 Anwar Shaikh, "An Introduction to the History of Crisis Theories", en U.S. Capitalism in Crisis, New York, Monthly Review Press, 1978, 236.

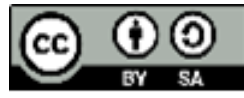


"economicismo" o "voluntarismo". En efecto, lo que subyace en toda la presentación de este autor es una crítica a la concepción derrumbista precedente como una concepción "fatalista" o "economicista". En particular, Grossmann discute la posición de Luxemburg a la que considera que lleva "implícita [...] la idea de un punto límite final del capitalismo [que es] irreconciliable con la concepción marxiana de la lucha de clases" y que por tanto "bien puede ser calificada como una recaída en el fatalismo quietista, en virtud de la cual no hay lugar para la lucha de clase". ${ }^{58}$ El argumento principal de Grossmann en este punto es que la superación del capitalismo no va a suceder sin la participación activa de la clase obrera, pero no simplemente porque la clase obrera es la que en definitiva va a tener que tomar en sus manos la organización consciente del proceso de producción social, sino en particular porque el momento del derrumbe va a depender de la masa de plusvalor disponible que, a su turno, depende de la lucha de clases. Así, hacia el final de su libro señala que la "irrupción" del derrumbe "en realidad, y dentro de ciertos límites, está sujeta a la influencia de enfrentamientos conscientes de las dos clases consideradas. [...] La lucha de la clase obrera por sus reivindicaciones cotidianas se vincula así con su lucha por el objetivo final. El objetivo final por el que la clase obrera combate, no se trata pues de un ideal introducido 'desde el exterior' en el movimiento obrero". 59

La contribución de Grossmann fue rápida y ampliamente discutida en varios círculos del marxismo. Sin embargo, salvo contadas excepciones, fue duramente criticada. En esencia, todas estas críticas pasaron por objetarle al argumento de Grossmann la rigidez que asumen las variables que componen su modelo. ${ }^{60} \mathrm{En}$ relación al vínculo entre desarrollo económico y acción política el enfoque de Grossmann fue discutido especialmente por los "comunistas de izquierda". ${ }^{61}$ Las contribuciones principales fueron las de Korsch, ${ }^{62}$ Pannekoek ${ }^{63}$ y Mattick. ${ }^{64}$ Considerémoslas sucintamente.

Korsch criticó a Grossmann por recaer en una línea interpretativa "objetivista" del curso de la sociedad capitalista que, en tanto tal, no es "capaz de suministrar la seria

\footnotetext{
${ }^{58}$ Grossmann, La ley ... op. cit., 19-20.

${ }^{59}$ Ibid., 388-89.

60 Véase Michael Charles Howard y John Edward King, "Henryk Grossmann and the Breakdown of Capitalism", Science \& Society, vol. 52, no 3, 1988, 290-309; Rick Kuhn, "Economic Crisis and Socialist Revolution: Henryk Grossman's Law of accumulation, Its First Critics and His Responses", Research in Political Economy, vol. 21, 2004, 181-221.

${ }^{61}$ Véase al respecto Marramao, Teoría del derrumbe... op. cit.

${ }^{62}$ Karl Korsch, "Fundamentos de una teoría revolucionaria de las crisis", en AA.VV., ¿Derrumbe del capitalismo o sujeto revolucionario?, México, Pasado y Presente, 1978 [1933], 107-23; Karl Korsch, "Algunos supuestos básicos para una disucisón materialista de la teoría de las crisis", en AA.VV., ¿Derrumbe del capitalismo op. cit., [1933] 124-31.

${ }^{63}$ Anton Pannekoek, "La teoría del derrumbe del capitalismo”, en AA.VV., ¿Derrumbe del capitalismo ... op.cit., [1934], 62-84.

${ }^{64}$ Paul Mattick, "La crisis mortal del capitalismo”, en AA.VV. ¿Derrumbe del capitalismo op. cit., [1933], 132-47; Paul Mattick, "Sobre la teoría marxiana de la acumulación y del derrumbe", en AA.VV. ¿Derrumbe del capitalismo, op. cit., [1934], 86-106; Paul Mattick, "The Permanent Crisis. Henryk Grossman's Interpretation of Marx's Theory Of Capitalist Accumulation”, International Council Correspondence, vol. 1, $\mathrm{n}^{\mathrm{o}} 2,1934.1-20$.
} 
garantía de la acción consciente de la clase proletaria en lucha por sus objetivos propios". ${ }^{65}$ En pocas palabras, Korsch buscó aplicarle a Grossmann la misma crítica que éste le aplicó a Luxemburg, esto es, que su teoría no dejaba lugar para la lucha de clases. A esta posición, y procurando no caer en lo que según este autor sería el extremo su opuesto del "subjetivismo", opuso "una posición auténticamente materialista" según la cual la crisis terminal tenía el papel del mito "soreliano" para la acción práctica de la clase obrera, esto es, sólo tenía sentido en cuanto motivaba la acción política revolucionaria. ${ }^{66}$ Por su parte, la crítica de Pannekoek fue en el mismo sentido. Según este autor, Grossmann explicaba el derrumbe del capitalismo "sin que haya una clase revolucionaria que combata y venza a la burguesía". ${ }^{67}$ Pero, a diferencia de Korsch, este autor presentaba una posición sobre la superación del capitalismo que buscaba preservar la determinación económica real de la acción política de la clase obrera presentando a las manifestaciones de la crisis económica determinando la voluntad del proletariado. "El socialismo", afirmaba este autor, "viene no porque el capitalismo se derrumbe económicamente [...] viene porque el capitalismo, tal como vive y crece, se vuelve cada vez más insoportable para los obreros y los lanza a la lucha". ${ }^{68}$ En contraposición, las contribuciones de Mattick buscaron defender los argumentos de Grossmann. Ante todo, Mattick rechazó "toda concepción mecánica del derrumbe del capital" por considerar que sólo veía un aspecto del "proceso dialéctico"69 y defendió a Grossmann por "limitarse por razones metodológicas, en su análisis de la ley de la acumulación, a la definición de supuestos meramente económicos”. Así, según este autor, Grossmann "no sost[uvo] un punto de vista 'puramente económico', sino dialéctico, para el cual toda abstracción es tan solo un medio para el reconocimiento de la realidad". 70 En consecuencia, de acuerdo a Mattick había que considerar que "la crisis mortal del capitalismo no significa que el sistema se suicida, sino que la lucha de clases asume formas que conducen al derrocamiento del sistema". ${ }^{71}$ Sin embargo, en cuanto a la conexión concreta entre desarrollo económico y acción política, la posición de este autor se alejabaaunque sin advertirlo- del enfoque de Grossmann. Para Mattick, en efecto, la lucha revolucionaria de la clase obrera por la superación del capitalismo se explicaba finalmente por la pauperización que sufría esta clase como producto de la crisis mortal del sistema. No es sino hasta el momento en que "el capital puede seguir existiendo únicamente en base a la pauperización absoluta y continua de las masas", afirmaba Mattick, "cuando trastroca esta lucha económica, resulte esto consciente o no para las masas, en lucha política". ${ }^{72}$

Consideremos las contraposiciones respecto del vínculo entre desarrollo económico y acción política que deja esta última instancia del debate. A primera vista, parece que las posiciones van desde un extremo economicista representado por Grossmann a otro extremo

\footnotetext{
${ }^{65}$ Korsch, Algunos supuestos básicos ... op. cit, 130.

${ }^{66}$ Idem.

${ }^{67}$ Pannekoek, La teoría del derrumbe ... op. cit., 70.

68 Ibid., 80-81.

${ }^{69}$ Mattick, La crisis mortal del capitalismo ... op. cit., 134.

${ }^{70}$ Mattick, Sobre la teoría ... op. cit., 86-87.

${ }^{71}$ Mattick, The Permanent ... op. cit., 20.

${ }^{72}$ Mattick, Sobre la teoría ... op. cit., 105.
} 
voluntarista representado por Korsch, pasando por posiciones intermedias representadas por Pannekoek y Mattick. Examinado más detenidamente, sin embargo, las posiciones tienen más en común de lo que parece. En el caso de Grossmann, sin bien el capitalismo no puede superarse sin la existencia del derrumbe económico y en este sentido puede ser caracterizado como un "economicista", la acción política revolucionaria de la clase obrera que lleva a cabo tal superación surge únicamente en reacción frente al derrumbe efectivo o inminente del sistema. Por tanto, como en el enfoque "voluntarista", en la argumentación de Grossmann la acción política revolucionaria de la clase obrera surge simplemente como afirmación de la libre voluntad humana contra el movimiento del capital. Más aún, incluso en el caso de la acción política sindical, que es la que se presenta explícitamente como el factor subjetivo del derrumbe del capitalismo, se trata de una acción política igualmente exterior al desarrollo económico en la medida en que su fuerza para imponer la masa de plusvalor que determina el momento del derrumbe no surge de la propia dinámica de la acumulación de capital sino de la mera lucha de clases. En este sentido, la concepción de Korsch respecto del vínculo entre desarrollo económico y acción política es exactamente la misma. En su argumentación también la acción política revolucionaria surge por fuera del desarrollo de la acumulación de capital y como reacción frente a éste, más no sea por la situación económica de crisis que alimenta el mito del derrumbe. Y esta misma desconexión es más evidente en las posiciones de Pannekoek y Mattick en la medida en que éstas no se apartan en lo esencial de las posiciones marxistas más tradicionales. En suma, todos estos enfoques pueden ser interpretados igualmente como "voluntaristas", en el sentido de que la acción revolucionaria brota desde fuera del desarrollo económico, o bien como "economicistas", en el sentido de que lo que determina el destino del capitalismo no es la acción política revolucionaria de la clase obrera sino el desarrollo económico. En consecuencia, detrás de la aparente contraposición entre "economicismo" y "voluntarismo" lo que subyace es la misma concepción respecto del vínculo entre desarrollo económico y acción política que está presente desde el inicio del debate: por un lado, está el desarrollo económico y por otro lado la acción política revolucionaria de la clase obrera que se opone a él.

\section{El método dialéctico y el vínculo entre desarrollo económico y acción política revolucionaria}

En el curso de nuestro análisis de la llamada controversia sobre el derrumbe del capitalismo hemos visto que, a pesar de las mutuas acusaciones esgrimidas por los contendientes, de la posición que adopte frente al "derrumbe" no surge ni la disposición a una acción política revolucionaria o reformista, ni la adopción de una concepción economicista o voluntarista de curso de la vida social. Como se ha procurado mostrar en cada instancia del debate, lo que habilita estas desconexiones es que se concibe al vínculo entre el desarrollo económico y la acción política como un vínculo externo. Esta concepción, en efecto, subyace a todas las posiciones porque, como se puede apreciar ahora, todas comparten el mismo argumento básico: la acción política que supera el 
capitalismo -sea reformista o revolucionaria- surge en reacción a una situación económica crítica, sea ésta la "miseria", la "crisis", la "explotación" o la "distribución de la riqueza". Aquí, la situación económica concreta se presenta siempre como el producto del proceso de acumulación de capital concebido como un fenómeno exclusivamente económico y que se desarrolla por sí mismo, esto es, abstraído de toda mediación política. A su vez, y como contraparte, la acción política de la clase obrera que supera el capitalismo forzosamente se presenta como un fenómeno ajeno a la acumulación de capital y cuya razón de existir resulta de este modo indefinida. En pocas palabras, desarrollo económico y acción política se presentan en un vínculo externo porque en todos los casos se los concibe desde el inicio como fenómenos autoconstituidos de manera previa a su relación. Realizado sobre la base de esta concepción común no debería llamar la atención que el debate no haya producido resultados concluyentes y más bien simplemente se haya diluido. Ante todo, si se parte de extirpar a un fenómeno de la unidad que lo constituye como tal inevitablemente se convierte lo convierte en una abstracción. Pero, además, no hay modo de restituir la unidad en cuestión una vez que se ha pretendido desarrollar por sí mismo lo que se ha extirpado de ella. Por eso, los intentos teóricos de responderse por la superación del capitalismo partiendo de romper la unidad que constituye el capitalismo mismo como modo de producción de la vida humana estaban condenados al fracaso desde el inicio. Esta forma de proceder, sin embargo, es completamente ajena al método de Marx, que precisamente se caracteriza por asir la unidad en la diferencia.

La conclusión de que las limitaciones de la controversia sobre el derrumbe surgen de las insuficiencias metodológicas que están implícitas en las concepciones en disputa fue advertida por Marramao a fines de la década de $1970 .{ }^{73}$ Este autor consideraba que, si se concebía a la crítica marxiana de la economía política tanto una crítica de las formas objetivas de la relación social como de las "formas de conciencia cosificadas", el propio método dialéctico de "exposición" desarrollado por Marx debía conducir necesariamente a una explicación "científica de la conciencia de clase" y de la superación del capitalismo. ${ }^{74}$ De este modo, concluía Marramao, "el proceso de la génesis del Klassenbewusstein [conciencia de clase] se explica por lo tanto a partir del proceso de producciónreproducción, desde el interior de la objetividad de las relaciones sociales, [en vez de ser] presupuesto como resultado de una autonomía irreductible". ${ }^{75}$ Desafortunadamente, este autor no realizó nunca este programa de investigación. Sin embargo, desde entonces -como de hecho ya lo advertía el mismo Marramao- en los debates marxistas comenzó a ponerse de manifiesto la relevancia del método dialéctico para la comprensión de la crítica marxiana de la economía política.

73 Giacomo Marramo, "Teoría de la crisis y el problema del estado. Al margen de la Konstitutionsproblematik”, en Marramo, G., Lo político ... op. cit. [1975], 118-53.

${ }^{74}$ Ibid., 140-41.

75 Ibid., 183. 
El primer paso en este sentido lo dio un grupo de marxistas alemanes ulteriormente reconocidos bajo la rúbrica de la "Nueva Lectura de Marx". ${ }^{76}$ En contraposición a las investigaciones tradicionales sobre el método dialéctico, en general vinculadas a la comprensión de las "grandes leyes" de la existencia de la realidad material, ${ }^{77}$ este grupo de autores se especializó en la investigación del papel del método dialéctico en la crítica marxiana de la economía política. Estas investigaciones, sin embargo, tuvieron dos limitaciones. En primer lugar, aún las más ambiciosas no pasaron de los primeros capítulos de El Capital y, en segundo lugar, hasta pasados varios años quedaron prácticamente encapsuladas en Alemania sin alcanzar nunca una difusión significativa. ${ }^{78} \mathrm{El}$ proyecto de vincular el método dialéctico con la crítica marxiana de la economía política recién cobró nuevo ímpetu, mayor concreción, y un verdadero alcance internacional, con los trabajos de lo que actualmente se conoce como la "Nueva dialéctica". ${ }^{79}$ De manera general, se puede decir que estas nuevas investigaciones encontraron que la estructura argumental de $E l$ Capital está organizada bajo una forma que encuentra inspiración formal en el despliegue de categorías presentado en la Lógica de Hegel. Así, la exposición de Marx es vista como el desarrollo del capital desde sus formas más simples hasta sus más complejas, en un movimiento que se caracteriza, parafraseando a Marx, como la "reproducción" de la vida interna de dicho objeto mediante el pensamiento. A su vez, en la medida en que el pasaje o la transición de una forma del capital a otra se la concibe como brotando del desarrollo de

\footnotetext{
${ }^{76}$ Para una presentación sintética de la génesis y evolución de esta corriente véase Riccardo Bellofiore y Tommaso Redolfi Riva, "The Neue Marx-Lektüre. Putting the critique of political economy back into the critique of society", Radical Philosophy, n 189, 2015, 24-36. Las obras fundantes de esta corriente son: Hans Georg Backhaus, "La dialéctica de la forma de valor", Dialéctica, n 4, 1978 [1969], 9-34; Helmut Reichelt, Sobre a estrutura lógica do conceito de capital em Karl Marx, Campinas, Editora Unicamp, 2013 [1970]; Alfred Schmidt, Historia y Estructura. Crítica del estructuralismo marxista, Madrid, Alberto Corazón Editor 1973 [1971].

77 Entre las obras de referencia principales se destacan: Friedrich Engels, Dialéctica de la naturaleza, Barcelona, Crítica. Grupo Editorial Grijalbo, 1979 [1883]; Georgi Plejanov, "La concepción monista de la historia”, en Obras escogidas, Tomo I, Buenos Aires, Quetzal, 1964 [1895], 7-276; Vladimir Ilich Lenin, "Cuadernos filosóficos”, en Lenin, V. I., Obras completas. Tomo XLII, Madrid, Progreso, 1974 [1916].

78 Para una evaluación crítica de los límites de este enfoque para dar cuenta de los fundamentos de la subjetividad revolucionaria de la clase obrera véase Guido Starosta, "Fetichismo y revolución en la teoría Marxiana contemporánea: una evaluación crítica de la Neue Marx-Lektüre y el Marxismo Abierto en clave metodológica", Ponencia presentada en el Simposio Sujeto Capital - Sujeto Revolucionario. Epistemología y análisis crítico de Sistema Capitalista y sus contradicciones, Universidad Autónoma Metropolitana, 2015.

${ }^{79}$ Véase una presentación sintética de esta corriente en Jim Kincaid, "The New Dialectic", en Bidet, J. y Kouvelakis. S. (eds.), Critical Companion to Contemporary Marxism, Leiden, Brill, 2009, 385-412. Las obras principales de esta corriente son: Tony Smith, The Logic of Marx's Capital. Replies to hegelian criticisms, Albany, SUNY press, 1990; Fred Moseley (ed.), Marx's method in Capital: a reexamination, Atlantic Highlands, Humanities Press, 1993; Fred Moseley y Martha Campbell (eds.), New investigations of Marx's method, Atlantic Highlands, Humanities press, 1997; Christopher Arthur, The new dialectic and Marx's Capital, Leiden, Brill, 2002; Robert Albritton y John Simoulidis (eds.), New Dialectics and Political Economy, Basingstoke, Palgrave Macmillan, 2003; Fred Moseley y Tony Smith (eds.), Marx's Capital and Hegel's Logic. A reexamination, Leiden, Brill, 2014. En castellano, véase Mario Robles Baez (ed.), Dialéctica y Capital. Elementos para una reconstrucción de la crítica de la economía política, México, Universidad Autónoma Metropoplitana, 2005.
} 
las contradicciones inmanentes de cada forma en cuestión, los vínculos entre las mismas son concebidos como inmanentes y necesarios, en abierta contraposición a la exterioridad propia del uso de la lógica formal. De esta manera, el método dialéctico cierra las puertas a cualquier tipo de conexión exterior entre los fenómenos bajo estudio. En concreto, esto significa que, si se es consecuente con este método, ya no cabe buscar solucionar el problema de la superación del capitalismo desarrollando por un lado la dinámica abstracta de la acumulación de capital y por otro lado la acción política o la conciencia revolucionaria de la clase obrera. En pocas palabras, es necesario hacer surgir a la acción revolucionaria de la clase obrera como una mediación necesaria de la realización de la propia dinámica de la acumulación de capital.

El desafío de vincular la acción revolucionaria de la clase obrera con el desarrollo de la acumulación de capital, sin embargo, no encontró lugar en esta corriente dentro de la teoría marxista. En cambio, recientemente ha aparecido en la literatura especializada un enfoque que, también sobre la base de realizar una lectura metodológicamente fundada de la crítica marxiana de la economía política, se ha preocupado especialmente por dilucidar esta cuestión. Este enfoque ha sido desarrollado originalmente por Iñigo Carrera ${ }^{80}$ y reelaborado ulteriormente en un contexto más amplio de debates por Starosta. ${ }^{81} \mathrm{El}$ alcance limitado del presente trabajo impide realizar aquí una presentación detallada de los argumentos presentados por estos autores, así como una discusión más comprehensiva de los textos de Marx en donde se presentan las determinaciones que hacen a la referida unidad entre acumulación de capital y acción política revolucionaria. No obstante, en lo que sigue repongo algunos puntos fundamentales de esta lectura de la crítica marxiana que permiten ofrecer una alternativa a las posiciones presentes en el debate sobre el 'derrumbe' del capitalismo.

Ante todo, esta lectura pone a la determinación de la conciencia por el ser social en el punto de partida de la crítica marxiana de la economía política. De este modo, se reconoce al desarrollo de la forma de valor con que inicia esta crítica como el develamiento de la forma enajenada en que los individuos organizan su proceso de vida social como "personificaciones" de las mercancías. En palabras de Marx, que en esta forma de sociedad los individuos están sujetos a "un movimiento de cosas bajo cuyo control se encuentran, en lugar de controlarlas" y que con su "acción", sólo pueden "confirmar" "las leyes de la

\footnotetext{
${ }^{80}$ Juan Iñigo Carrera, El capital: razón histórica, sujeto revolucionario y conciencia, Buenos Aires, Imago Mundi, 2013 [2003], capítulo 1; Juan Iñigo Carrera, "Crisis de sobreproducción general y crisis absoluta del modo de producción capitalista", Razón y Revolución, no 18, 2008, 95-110; Juan Iñigo Carrera, "The Historical Determination of the Capitalist Mode of Production and of the Working Class as the Revolutionary Subject", Critique: Journal of Socialist Theory, vol. 42, n 4, 2014, 555-72.

${ }^{81}$ Guido Starosta, "El sistema de maquinaria y las determinaciones de la subjetividad revolucionaria en los Grundrisse y El Capital”, en Caligaris G. y Fitzsimons A. (ed.), Relaciones económicas y políticas: aportes para el estudio de su unidad con base en la obra de Karl Marx, Buenos Aires, Facultad de Ciencias Económicas de la Universidad de Buenos Aires, 2012, 92-136; Guido Starosta, Marx's Capital, Method and Revolutionary Subjectivity, Leiden, Brill, 2015; Starosta, Fetichismo y revolución ... op. cit.
} 
naturaleza inherente a las mercancías". ${ }^{82}$ En suma, tal como lo sintetiza Iñigo Carrera, que "la conciencia y voluntad libres del productor de mercancías" no es otra cosa que "la forma en que se realiza la enajenación de su conciencia y voluntad como atributos de la mercancía". ${ }^{83}$ Desde el punto de vista del método que fundamenta la crítica marxiana de la economía política, este reconocimiento del vínculo existente entre la mercancía en tanto relación social general y la conciencia deja dos conclusiones centrales para la investigación sobre la unidad entre el desarrollo económico y la acción política de la clase obrera. En primer lugar, que desde este momento de la exposición dialéctica en adelante no puede surgir acción política alguna que no sea el vehículo de la realización de la relación económica. En segundo lugar, y en consecuencia, que la necesidad de la acción revolucionaria de la clase obrera sólo puede surgir del desarrollo de esta relación económica en sus más formas concretas de existencia.

Desde un punto de vista "materialista, y por consiguiente científico", el único lugar de donde puede surgir una transformación en la conciencia de una clase de individuos o, como lo pone Marx, en "sus representaciones intelectuales", es de una transformación en "el proceso de producción inmediato de su existencia". ${ }^{84}$ En consecuencia, de acuerdo a este enfoque, para explicarse la necesidad del desarrollo de una conciencia y por lo tanto de una acción revolucionaria, hay que avanzar en el despliegue de la relación mercantil hasta su forma de existencia como vehículo del desarrollo de las fuerzas productivas. Marx presenta al capital como esta forma concreta de la relación social general en el examen de las formas de producción de plusvalor relativo. En particular en su forma más potente, que es el "sistema de la maquinaria", encontramos allí que las transformaciones en la subjetividad de la clase obrera pasan, de una parte, por la degradación del obrero a la condición de "apéndice viviente" de la maquinaria y, de otra parte, a su transformación en "población superflua [...] para la autovalorización del capital". ${ }^{85}$ Al mismo tiempo, sin embargo, esta misma transformación en el proceso de trabajo que mutila la subjetividad productiva de la clase obrera lleva consigo la producción de un "individuo totalmente desarrollado, para el cual las diversas funciones sociales son modos alternativos de ponerse en actividad". 86 Ahora bien, esta producción de un "individuo plenamente desarrollado" choca con la producción de un individuo que no puede controlar las potencias sociales de su propia actividad por estar enajenado en el capital. Esta contradicción inmanente a la producción capitalista está desarrollada más plenamente por Marx en sus borradores. Allí, como lo discute in extenso Starosta, ${ }^{87}$ se presenta a la producción de este "individuos plenamente desarrollado" directamente como la forma esencial en que "el capital trabaja

\footnotetext{
${ }^{82}$ Karl Marx, El capital. Crítica de la economía política. Tomo I/Vol. 1, México: Siglo XXI, 1999 [1867], 91; 105-106.

${ }^{83}$ Juan Iñigo Carrera, Conocer el capital hoy. Usar críticamente El Capital. Volumen I: La mercancía, o la conciencia libre como forma de la conciencia enajenada, Buenos Aires, Imago Mundi, 2007, 59.

${ }^{84}$ Karl Marx, El capital ... op. cit. Vol. 2, 453 n.

${ }^{85}$ Ibid., 515-24.

${ }^{86}$ Ibid., 594.

${ }^{87}$ Starosta, "El sistema ... op. cit.
} 
[...] en favor de su propia disolución". ${ }^{88}$ Así, en contraposición a visión marxista tradicional según la cual la tendencia general del capital es a degradar la subjetividad productiva de la clase obrera, ${ }^{89}$ aquí se presenta como eje a la tendencia a desarrollar al obrero con la capacidad para controlar de manera plenamente consciente su proceso de trabajo y, en consecuencia, su participación en la organización del proceso de vida social. Por lo tanto, lo que en un caso lleva a presentar un vínculo exterior entre el desarrollo económico y la subjetividad revolucionaria, en el otro lleva a presentar un vínculo inmanente entre los mismos.

El último punto esencial en el descubrimiento de la acción revolucionaria de la clase obrera como un momento del desarrollo del capital -en rigor, ya implícito en el punto anterior- es el reconocimiento de la contradicción absoluta que existe entre el carácter privado del trabajo que fundamenta la forma de valor y la tendencia del capital a socializar el trabajo. Aunque el examen del proceso de producción de plusvalor relativo y de la concentración y centralización del capital ya ponen en evidencia esta contradicción, Marx recién la presenta explícitamente en el célebre apartado sobre la "tendencia histórica de la acumulación capitalista". Allí, esta contradicción se presenta en dos pasos. En primer lugar, como una contradicción entre la producción fundada en "la propiedad privada del trabajador sobre sus medios de producción" y la producción capitalista donde los medios de producción están "socialmente concentrados". Y, en segundo lugar, como una contradicción propia del modo de producción capitalista, donde la "socialización [...] del trabajo" ya no pasa por expropiación del "trabajador que labora por su propia cuenta", sino por la "centralización de los capitales". Luego, en cuanto esta socialización choca por definición contra el propio carácter privado del trabajo, "la centralización de los medios de producción y la socialización del trabajo alcanzan un punto en que son incompatibles con su corteza capitalista". ${ }^{90} \mathrm{Y}$ en cuanto se trata de un movimiento propio del capital no cabe aquí buscar al sujeto revolucionario en otro lado que no sea en el desarrollo de este mismo movimiento. Por eso, y en correspondencia con el descubrimiento del desarrollo de la subjetividad productiva capaz de tomar en sus manos el control consciente de la producción social, Marx presenta aquí al crecimiento de la "rebeldía de la clase obrera, una clase [...] que es disciplinada, unida y organizada por el mecanismo mismo del proceso capitalista de producción". ${ }^{91}$ En suma, tal como lo presenta Iñigo Carrera, la socialización del trabajo privado "es la contradicción que sintetiza las potencias históricas y el límite del modo de producción capitalista". ${ }^{92}$ Luego, en este límite nos encontramos "al capital requiriendo, como una necesidad que brota de su mera reproducción inmediata", la abolición misma del trabajo privado y, en consecuencia, "de ser personificado por una conciencia y voluntad que se haya liberado de toda enajenación y, por lo tanto, que se haya liberado de toda

${ }^{88}$ Karl Marx, Elementos fundamentales para la crítica de la economía política (Grundrisse) 1857-1858. Volumen 2, México, Siglo XXI, 1997 [1857-1858], 222.

${ }^{89}$ Cfr. el trabajo clásico de Harry Braverman, Trabajo y capital monopolista. La degradación del trabajo en el siglo XX, México, Nuestro Tiempo, 1987 [1974].

${ }^{90}$ Ibid., 952-953.

${ }^{91}$ Ibid., 953.

92 Iñigo Carrera, El capital ... op. cit., 37. 
determinación como personificación del capital”. La realización de este salto adelante en las fuerzas productivas del trabajo social tiene que tomar forma, por consiguiente, en "una revolución social en la que el sujeto material de ese desarrollo, o sea, la clase obrera, no se limita ya a aniquilar a la burguesía transformando al capital en una propiedad inmediatamente social, sino que aniquila al capitalismo mismo". 93

El "derrumbe" del capitalismo, por consiguiente, resulta inevitable. Pero no por el advenimiento de una crisis económica terminal de sobreproducción o de caída de la tasa de ganancia, sino porque la propia acumulación de capital necesita realizar un salto adelante en la socialización del trabajo privado que acaba con el trabajo privado mismo $\mathrm{y}$, en consecuencia, con la enajenación de la capacidad para organizar el trabajo social en el capital. El punto esencial de este enfoque es que la acción política revolucionaria de la clase obrera que supera el capitalismo surge aquí como una necesidad del capital de producir plusvalor relativo. Esto es, porque el capital necesita avanzar en la centralización del capital para producir plusvalor es que necesita investir a la clase obrera con la capacidad para organizar de manera plenamente consciente el proceso entero de producción social y, por lo tanto, con la capacidad para abolirlo como el sujeto enajenado de este mismo proceso. En otras palabras, el proceso acabado de socialización del trabajo que emerge como una necesidad del capital está portado en la acción política revolucionaria de la clase obrera. Por tanto, a diferencia del enfoque marxista tradicional que, por presentar en un vínculo exterior entre el desarrollo económico y la acción política revolucionaria, forzosamente cae en el dilema de "economicismo" vs. "voluntarismo", este enfoque logra presentar una explicación consistente de la superación del modo de producción capitalista como el producto tanto del desarrollo del capital como de la acción política revolucionaria de la clase obrera.

\section{Conclusión}

Lo primero que salta a la vista en el análisis de las principales posiciones presentadas en el llamado debate sobre el derrumbe del capitalismo es que de la concepción que se adopte de la dinámica de la acumulación de capital no se desprende un tipo particular de acción política. En efecto, hemos visto que autores de las tendencias políticas más diversas caen indistintamente en ambos lados del debate respecto de la posibilidad de la acumulación de capital para reproducirse sobre su propia base. Como hemos advertido, esto sucede porque todos los autores que participan del debate tienen la misma concepción del vínculo entre el desarrollo económico y la acción política. Para todos, el desarrollo económico transcurre por sí mismo generando situaciones económicas críticas a las que se opone la acción política de la clase obrera. Así, tanto uno como el otro se presentan como fenómenos autoconstituidos previamente a su relación $\mathrm{y}$, por tanto, vinculados exteriormente. Luego, es por entero indiferente que la acción política de la clase obrera sea reformista o la revolucionaria, ya que en cualquier caso no se deriva del desarrollo económico.

${ }^{93}$ Ibid., 39-40 
A su vez, hemos visto que el curso final del debate donde, puesto en evidencia la desconexión entre desarrollo económico y tipo de acción política, se termina girando hacia una confrontación donde la cuestión se reduce al carácter "economicista" o "voluntarista" con que se busca dar cuenta del destino histórico del capitalismo, tiene las mismas limitaciones. Como la relación entre desarrollo económico y acción política sigue siendo una relación exterior, las posiciones no pueden sino recaer permanentemente en ambos polos de dicho dilema sin poder superarlo; esto es, nunca pueden desarrollar el papel de un polo en la superación del capitalismo sin acabar negando al otro. En concreto, si se afirma que la acumulación de capital lleva por sí misma al derrumbe del sistema entonces se cae en el economicismo, y si a continuación se sostiene que la superación del capitalismo depende de la acción política de la clase obrera por fuera del desarrollo económico entonces se cae en el voluntarismo. Lo que no se puede hacer nunca bajo esta concepción es afirmar las dos cosas al mismo tiempo.

En contraposición a esta forma de abordar la cuestión de la superación del capitalismo, en la última parte de este trabajo hemos visto que una lectura metodológicamente fundada de la crítica de la economía política permite superar los principales dilemas presentados en el debate. Este abordaje contrapone, en primer lugar, un método de conocimiento que "reproduce la vida interna del objeto" a examinar donde la transición entre cada una de sus determinaciones pasa por el desarrollo de las contradicciones inmanentes a cada forma en cuestión y, en consecuencia, no deja lugar a ningún tipo de vínculo exterior entre el desarrollo económico y la acción política. En segundo lugar, este abordaje contrapone el reconocimiento de la acción de los individuos como la portadora de la reproducción del capital. De este modo, se supera el dilema entre "economicisimo" y "voluntarismo" en cuanto la afirmación de la que la superación del capitalismo depende del desarrollo de la acumulación de capital lleva consigo la afirmación de que el capitalismo se supera a través de la acción revolucionaria de la clase obrera.

\section{Bibliografía}

Albritton, Robert y Simoulidis, John, New Dialectics and Political Economy, Basingstoke, Palgrave Macmillan, 2003.

Angus, Ian, "The origin of Rosa Luxemburg's slogan 'socialism or barbarism"”, en John Riddell's Marxist Essays and Commentary, [en línea] 〈https://goo.gl/qzMGqL〉.

Arthur, Christopher, The new dialectic and Marx's Capital, Leiden, Brill, 2002.

Backhaus, Hans Georg, "La dialéctica de la forma de valor", Dialéctica, no 4, 1978 [1969], 9-34.

Bauer, Otto, "La acumulación de capital", en Colletti, L. (ed.), El Marxismo y el "Derrumbe" del Capitalismo, México, Siglo XXI, 1978 [1913], 339-64.

Bellofiore, Riccardo, y Redolfi Riva, Tommaso, "The Neue Marx-Lektüre. Putting the critique of political economy back into the critique of society", Radical Philosophy, ${ }^{\circ} 189,2015,24$ 36.

Bernstein, Eduard,. "La teoría del derrumbe y la politica colonial", en Bernstein, E., Las premisas del socialismo y las tareas de la socialdemocracia, México, Siglo XXI, 1982 [1898], 6676. 
Boudin, Louis B., The Theoretical System of Karl Marx in the Light of Recent Criticism, Chicago, Charles H. Kerr \& Company, 1920 [1907].

Bujarin, Nikolai, El imperialismo y la acumulación de capital, Buenos Aires, Tiempo Contemporáneo, 1974 [1924].

Bulgákov, Serguéi Nikoláievich, Sobre el problema de los mercados en la producción capitalista, traducido por Alejandro Ariel Gonzalez, Buenos Aires, Mimeo, 2015 [1897].

Braverman, Harry, Trabajo y capital monopolista. La degradación del trabajo en el siglo XX, México, Nuestro Tiempo, 1987 [1974].

Colletti, Lucio, "Bernstein y el marxismo de la segunda internacional", en Colletti, L., Ideología y Sociedad, Barcelona, Fontanella, 1975 [1968], 71-162.

, "Introducción", en Colletti, L. (ed.), El marxismo y el "derrumbe" del capitalismo, México, Siglo XXI, 1978 [1970].

Danielson, Nikolai F., Histoire du Developpement économique de la Russie depuis l'Affranchissement des serfs, Paris, V. Girard and E. Briere, 1902 [1893].

Eckstein, Gustav, "Rosa Luxemburg's The Accumulation of Capital: A Critique", en Day, R. y Gaido, D. (eds.), Discovering Imperialism: Social Democracy to World War I, Leiden, Brill, 2012 [1913], 695-712.

Engels, Friedrich, Dialéctica de la naturaleza, Barcelona, Crítica Grijalbo, 1979 [1883].

Fano, Ester, "Los países capitalistas, desde la guerra mundial hasta la crisis de 1929", en AA.VV., La crisis del capitalismo en los años '20. Análisis económico y debate estratégico en la tercera internacional, México, Pasado y Presente, 1981 [1976], 91-131.

Gaido, Daniel y Quiroga, Manuel, "La teoría del imperialismo de Rosa Luxemburg y sus críticos: la era de la Segunda Internacional", Critica Marxista, n 37, 2013, 113-32.

Grossmann, Henryk, La ley de la acumulación y del derrumbe del sistema capitalista, México, Siglo XXI [1979] 1929.

Hilferding, Rudolf, El capital financiero, Madrid, Tecnos, 1963 [1910].

Howard, Michael Charles y King, John Edward, "Henryk Grossmann and the Breakdown of Capitalism", Science \& Society, vol. 52, n 3, 1988, 290-309.

Iñigo Carrera, Juan, El capital: razón histórica, sujeto revolucionario y conciencia, Buenos Aires, Imago Mundi, 2013 [2003].

, Conocer el capital hoy. Usar críticamente El Capital. Volumen I: La mercancía, o la conciencia libre como forma de la conciencia enajenada, Buenos Aires, Imago Mundi, 2007.

, "Crisis de sobreproducción general y crisis absoluta del modo de producción capitalista", Razón y Revolución, $\mathrm{n}^{\circ}$ 18, 2008, 95-110.

- "The Historical Determination of the Capitalist Mode of Production and of the Working Class as the Revolutionary Subject", Critique: Journal of Socialist Theory, vol. 42, no 4 , $2014,555-572$.

Jacoby, Russell, "The Politics of Crisis Theory: Toward the Critique of Automatic Marxism II", Telos 23, Spring, 1975, 3-52.

Kautsky, Karl, The Class Struggle (Erfurt Program), Chicago, C. H. Kerr \& Company CoOperative, 1910 [1892].

, La doctrina socialista. Replica al libro de Eduardo Bernstein Socialismo Teórico y Socialismo Práctico, Buenos Aires, Claridad, 1966, [1899].

, "Teoría de las crisis", en Colletti, L. (ed.), El Marxismo y el "Derrumbe" del Capitalismo, México, Siglo XXI, 1978 [1901], 189-236. 
—, The Materialist Conception of History, New Haven, Yale University Press, 1988 [1927]. Kincaid, Jim, "The New Dialectic", en Bidet, J. y Kouvelakis, S. (eds.), Critical Companion to Contemporary Marxism, Leiden, Brill, 2009, 385-412.

Kindersley, Richard, The First Revisionists. A Study of Legal Marxsim in Russia, Oxford, Clarendon Press, 1962.

Korsch, Karl, "Algunos supuestos básicos para una disucisón materialista de la teoría de las crisis", en AA.VV., ¿Derrumbe del capitalismo o sujeto revolucionario?, México, Pasado y Presente, 1978 [1933], 124-31.

, "Fundamentos de una teoría revolucionaria de las crisis", en AA.VV., ¿Derrumbe del capitalismo o sujeto revolucionario?, México, Pasado y Presente, 1978 [1933], 107-23.

Krätke, Michael, "On the Beginnings of Marxian Macroeconomics", en Dellheim, J. y Frieder, O., Rosa Luxemburg: A Permanent Challenge for Political Economy. On the History and the Present of Luxemburg's “Accumulation of Capital”, Palgrave Macmillan, 2016, 123-155.

Kuhn, Rick, "Economic Crisis and Socialist Revolution: Henryk Grossman's Law of accumulation, Its First Critics and His Responses", Research in Political Economy, vol. 21, 2004, 181221.

Lenin, Vladimir Ilich, "El llamado problema de los mercados", en Lenin, V. I., Obras completas. Tomo I, Madrid, Akal, 1974 [1893], 85-138.

, "El contenido económico del populismo y su crítica en el libro del señor Struve. (Reflejo del marxismo en la literatura burguesa)", en Lenin, V. I., Obras completas. Tomo I, Madrid, Akal, 1974 [1894], 351-523.

, "Para una caracterización del romanticismo económico. Sismondi y nuestros sismondistas nacionales", en Lenin, V. I., Obras completas. Tomo II, Madrid, Akal, 1974 [1897], 121258.

"El desarrollo del capitalismo en Rusia: proceso de la formación del mercado interior para la gran industria", en Lenin, V. I., Obras Completas. Tomo III, Madrid, Akal, 1974 [1899].

, ¿Qué hacer? Problemas candentes de nuestro movimiento", en Lenin, V. I., Obras completas. Tomo V, Madrid, Akal, 1976 [1902], 351-536.

, "Carta a la redacción del periódico Sotsial-Demokrat", en Lenin, V. I. Correspondencia. Tomo II, Buenos Aires, Editorial Estudio, 1968 [1913], 88-89.

, "Letter To the Editor of Bremer Bürger-Zeitung", en Lenin, V. I., Collected Works. Vol. 43, Moscow, Progress Publishers, 1977 [1913], 332-33.

, "Carlos Marx (Breve esbozo biográfico con una exposición del marxismo)", en Lenin, V. I., Obras completas. Tomo XXII, Madrid: Akal, 1977 [1915], 133-83.

, "Cuadernos filosóficos", en Lenin, V. I., Obras completas. Tomo XLII, Madrid, Progreso, 1974 [1916].

Luxemburg, Rosa, ¿Reforma o revolución?, Buenos Aires, Ediciones Luxemburg, 2010 [1899].

-, La acumulación de capital, Buenos Aires, S/R, 1968, [1913].

, "El folleto Junius: la crisis de la socialdemocracia alemana", en Luxemburg, R., Obras Escogidas, Izquierda Revolucionaria, 2008 [1916], 265-344.

"La acumulación de capital o en qué han convertido los epigonos la teoría de Marx. Una anticrítica", en Luxemburg, R., La acumulación de capital, Buenos Aires, S/R, 1968 [1921], 437-547.

Marramo, Giacomo, "Teoría de la crisis y el problema del estado. Al margen de la Konstitutionsproblematik", en Marramao, G., Lo político y las transformaciones. Crítica 
del capitalismo e ideologías de la crisis entre los años 20 y 30, México, Pasado y Presente, 1982 [1975], 118-53.

, "Teoría del derrumbe y el capitalismo organizado en las discusiones del 'extremismo histórico"”, en Marramao, G., Lo político y las transformaciones. Crítica del capitalismo e ideologías de la crisis entre los años 20 y 30, México, Pasado y Presente, 1982 [1976], 73117.

Marx, Karl, Elementos fundamentales para la crítica de la economía política (Grundrisse) 18571858. Volumen 2, México, Siglo XXI, 1997 [1857-1858].

—_, El capital. Crítica de la economía política, Tomo I/Vol. 2, México, Siglo XXI,1999 [1867].

— El capital. Crítica de la economía política. Tomo I/Vol. 3., México, Siglo XXI, 2000 [1867].

—, El capital. Crítica de la economía política. Tomo I/Vol. 1, México, Siglo XXI, 1999 [1867].

Mattick, Paul, "La crisis mortal del capitalismo”, en AA.VV., ¿Derrumbe del capitalismo o sujeto revolucionario?, México, Pasado y Presente, 1978 [1933],132-47.

, "Sobre la teoría marxiana de la acumulación y del derrumbe", en AA.VV., ¿Derrumbe del capitalismo o sujeto revolucionario?, México, Pasado y Presente, 1978 [1934], 86-106.

, "The Permanent Crisis. Henryk Grossman's Interpretation of Marx's Theory Of Capitalist Accumulation", International Council Correspondence, vol. 1, n 2, 1934, 1-20.

Moseley, Fred, Marx's method in Capital: a reexamination, Atlantic Highlands, Humanities Press, 1993.

Moseley, Fred, y Martha Campbell, New investigations of Marx's method, Atlantic Highlands, Humanities press, 1997.

Moseley, Fred, y Tony Smith, Marx's Capital and Hegel's Logic. A reexamination, Leiden, Brill, 2014.

Pannekoek, Anton, "Review of Rosa Luxemburg: The Accumulation of Capital: A Contribution to the Economic Explanation of Imperialism”, Day, R. y Gaido, D., Discovering Imperialism: Social Democracy to World War I, Leiden, Brill, 2012 [1913], 675-94.

—, "La teoría del derrumbe del capitalismo", en AA.VV., ¿Derrumbe del capitalismo o sujeto revolucionario?, México, Pasado y Presente, 1978 [1934], 62-84.

Plejanov, Georgi, "La concepción monista de la historia", en Plejanov, G., Obras escogidas. Tomo I, Buenos Aires, Quetzal, 1964 [1895], 7-276.

Reichelt, Helmut, Sobre a estrutura lógica do conceito de capital em Karl Marx, Campinas, Editora Unicamp, 2013 [1970].

Robles Baez, Mario, Dialéctica y Capital. Elementos para una reconstrucción de la crítica de la economía política, México, Universidad Autónoma Metropoplitana, 2005.

Rosdolsky, Roman, Génesis y estructura de El Capital de Marx, México, Siglo XXI, 1989 [1968].

Schmidt, Alfred, Historia y Estructura. Crítica del estructuralismo marxista, Madrid, Alberto Corazón Editor, 1973 [1971].

Schmidt, Conrad, "Contribución a la teoría de las crisis comerciales y de la sobreproducción", en Colletti, L. (ed.), El Marxismo y el "Derrumbe” del Capitalismo, México, Siglo XXI, 1978 [1901], 177-86.

"Rosa Luxemburg: Die Akkumulation des Kapitals", Archiv für Sozialwissenschaft und Socialpolitik, $\mathrm{n}^{\circ} 39,1915,256-61$.

Shaikh, Anwar, "An Introduction to the History of Crisis Theories", en U.S. Capitalism in Crisis, New York, Monthly Review Press, 1978, 219-41. 
Smith, Tony, The Logic of Marx's Capital. Replies to hegelian criticisms, Albany, SUNY press, 1990.

Starosta, Guido, "El sistema de maquinaria y las determinaciones de la subjetividad revolucionaria en los Grundrisse y El Capital", en Caligaris, G. y Fitzsimons, A., Relaciones económicas y políticas: aportes para el estudio de su unidad con base en la obra de Karl Marx, Buenos Aires, Facultad de Ciencias Económicas de la Universidad de Buenos Aires, 2012, 92-136. , "Fetichismo y revolución en la teoría Marxiana contemporánea: una evaluación", Ponencia presentada en el Simposio Sujeto Capital - Sujeto Revolucionario. Epistemología y análisis crítico de Sistema Capitalista y sus contradicciones, Universidad Autónoma Metropolitana, Unidad Xochimilco, 2015. , Marx's Capital, Method and Revolutionary Subjectivity, Brill, 2015.

Sternberg, Frtiz, El imperialismo, México, Siglo XXI, 1979 [1926].

Sweezy, Paul, Teoría del desarrollo capitalista, México, Fondo de Cultura Económica, 1973 [1942].

Tudor, Henry, y Tudor, J. M., Marxism and social democracy: the revisionist debate 1896-1898, Cambridge, Cambridge University Press, 1988.

Tugán-Baranovski, Mijaíl, Las crisis industriales en la Inglaterra moderna, sus causas e influencia sobre la vida social, traducido por Alejandro Gonzalez, Buenos Aires, Mimeo, 2015 [1894].

—, "Studies on the Theory and the History of Business Crises in England, Part I: Theory and History of Crises, Chapter I and VII", Research in Political Economy, vol. 18, 2000 [1901], 53-110.

Venturi, Franco, El populismo ruso, Madrid, Alianza, 1981 [1952].

Von Laue, Theodore H., "The Fate of Capitalism in Russia: The Narodnik Version", American Slavic and East European Review, vol. 13, $\mathrm{n}^{\circ}$ 1, 1954, 11-28.

Vorontsov, Vasily, Sud'by kapitalizma v Rossii, S. Peterburg, Stasivlevicha, 1882.

Walicki, Andrzej, Populismo y marxismo en Rusia, Barcelona, Editorial Estela, 1971 [1969].

Zasúlich, Vera, "Carta de Vera Zasúlich a Karl Marx del 16 de febrero de 1881", en Marx, K. y Engels, F., Escritos sobre Rusia II. El porvenir de la comuna rusa, México, Pasado y Presente, 1980 [1881], 29-30. 